\title{
Combined robot-based manufacturing and machining of multi-material components
}

\author{
Marcel Droß ${ }^{1} \cdot$ Max Albergt $^{1} \cdot$ Martin David ${ }^{1} \cdot$ Ann-Kathrin Reichler ${ }^{1} \cdot$ Hans-Werner Hoffmeister $^{1} \cdot$ Klaus Dröder $^{1}$
}

Received: 18 December 2020 / Accepted: 29 March 2021 / Published online: 24 April 2021

(C) The Author(s) 2021

\begin{abstract}
The growing demand for individualized products is becoming more and more significant and leads to a reduction in batch sizes. In particular, the production of multi-material components for lightweight design presents new challenges to the manufacturing process. This is evident when it comes to the production of individual parts, as today's processes are characterized by high tool costs and manual operations. The described challenge can be overcome by a robot-based manufacturing cell allowing the use of a novel, modular process chain in which metal parts are mechanically pre-treated, subsequently completed by additive plastic application, and afterwards finalized in a machining step to achieve the required surface qualities and geometries. In order to realize the novel process chain, robot-based solutions for free-form metal sheet processing, increased interlayer bonding strength of plastic, and multi-material machining with integrated chip extraction have to be found. Therefore, this paper presents the first approach of a robot-guided surface structuring end-effector and a concept for a direct extraction hood, which is able to be adapted specifically to the movement of the robot and the part surface, so free-form surfaces can be machined. Based on this, first experimental studies for increasing the interlayer bonding strength of plastic were carried out using an extruder set up to applicate thermoplastics onto metal at high deposition rates. To define the positioning accuracy for a robot-guided structuring process, different point to point movements have been investigated.
\end{abstract}

Keywords Flexible manufacturing system $\cdot$ Robot $\cdot$ Multi-material manufacturing

\section{Introduction}

The increasing demand for individualized products is becoming more and more important, resulting in a reduction of batch sizes to be manufactured. Especially in the production of multi-material components for the lightweight design, new challenges arise for the manufacturing process. This is particularly evident in the production of individual parts as current processes are characterized by high tool costs and manual work.

For this purpose, a robot-based manufacturing cell has been set up in which multi-material components can be manufactured by using pre-produced metal parts (e.g., CNCmachined parts). The metal parts are mechanically pre-treated

Marcel Droß

m.dross@tu-braunschweig.de

1 Institute of Machine Tools and Production Technology, Technische Universität Braunschweig, Langer Kamp 19b,

38106 Braunschweig, Germany by a surface structuring process and additively completed with plastic using an extruder. Afterwards, a machining finalization step is performed to achieve the required surface quality for the applied plastic and the pre-produced metal components. In comparison to existing production systems, the modularity of the robot-based manufacturing cell allows a flexible manufacturing of multi-material components in one machine setup. The first approach of that process chain for manufacturing multi-material parts based on metal and plastic was already presented in [1]. Thereby, a structuring process of preproduced metal surfaces was combined with a subsequent extruder-based plastic application. To achieve an adequate surface finish, a milling process was performed at the end. It was also shown that by creating interlocking structures on the metal surface, the joint strength between metal and plastic was significantly increased.

This new manufacturing approach leads to a process with great product and volume flexibility and high scalability. However, a new robot-guided end-effector for freeform surface structuring and an in-process chip extraction for the multi-material milling process have to be developed. 
Therefore, this paper presents the first approach of such a surface structuring end-effector and a concept for a direct extraction hood, which is able to adapt specifically to the movement of the machining spindle and the workpiece surface. Furthermore, first results of the implementation of the process chain addressing two of the main challenges will be presented. On the one hand, experimental results for increasing the interlayer bonding strength of the extruder-based applied plastic will be shown; and on the other hand, motion studies for a future application of the robot-based end-effector for surface structuring are carried out.

\section{Challenges in robot-based manufacturing of metal-plastic components}

A combined modular process chain for manufacturing metalplastic components is associated with several challenges that need to be addressed. Main challenges to the manufacturing process are shown in Fig. 1.

In particular, the connection between the metal and the plastic part is crucial to the overall component strength. The results from previous experiments $[1,2]$ show that the interlocking structures are a promising approach to combine metal sheets and plastic components. However, by inserting interlocking structures in the metal surface, it is necessary to ensure a full contact with the applied plastic. In section 2.1, other technologies for increased bonding strength between metal and plastic will be described. To realize a freeform robot-based structuring process, a lightweight tool has to be developed. The tool should be based on well-known solutions of robot-based metal sheet processing. For this reason, current research and technologies are presented in section 2.2.

The interlayer bonding strength between plastic and plastic is responsible for the specific component strength since a failure should always occur cohesively between the layers and not adhesively in a multi-material component. Hence, new approaches of increasing the interlayer strength for an extruder-based plastic application with high deposition rates need to be investigated. A first approach was presented in [1].

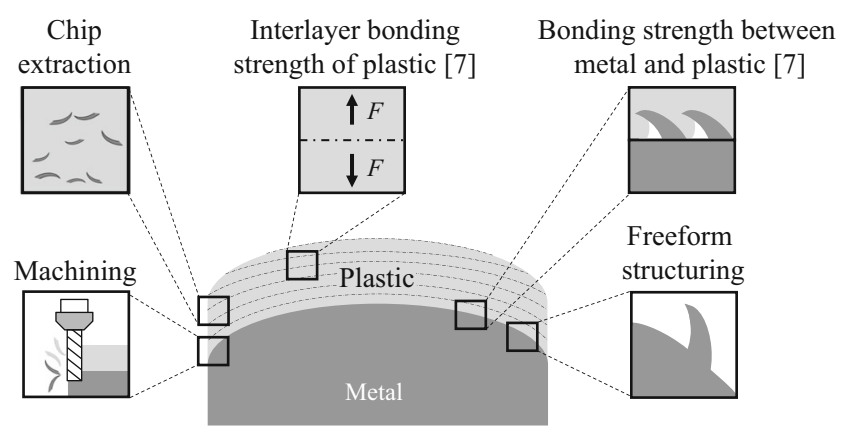

Fig. 1 Challenges in manufacturing multi-material components based on metal and plastic in a robot-based manufacturing cell
The variation of the printing temperature between 190 and $220{ }^{\circ} \mathrm{C}$ increases the bonding strength up to $40 \mathrm{MPa}$ in $\mathrm{z}$ direction (TOYOLAC® 100 X01, maximum tensile strength for injection molded parts is $44 \mathrm{MPa}$ ). In this paper, different approaches for improving the interlayer strength by modifying the layer surface to generate interlocking effects after the printing process are presented and analyzed in section 4.1.

Another challenge is the milling process itself. For different materials with various densities, specific cutting speeds and depths are needed. Furthermore, specific parameters for a robot-guided milling process need to be analyzed. At the end, the chips and dust of the milling process have to be removed to achieve a fully automated process chain. To give an overview about current solutions, section 2.3 presents selected technologies and research in effective chip collection and dust extraction.

\subsection{Bonding technologies for metal-plastic components}

In Fig. 2 ,a schematic illustration of typical bonding technologies for metal-plastic composites is shown. As presented in [1], the bonding strengths of the interlocking structures described in [2] show promising results with loads up to $1681.3 \pm 593.8 \mathrm{~N}$ depending on the depth of the structure. Interlocking structures like Grip MetalTM do not achieve these high loads due to the thinner and highly consolidated roots of the structures, which result from the chipping process [3]. Other technologies, like the "IGEL technology" [4] or laser structuring [5], have major disadvantages like introducing heat into the surface of the part which results in thermal tensile stresses weakening the connection between metal and plastic. Furthermore, the application rate of these processes is low and they are currently only performed on even surfaces. Besides the different macro- and microscopic structures, adhesion promoters are used to bond plastic and metal. However, this bonding technology requires an additional process step. As can be seen from the literature, only interlocking structures are well suited for the production of metal-plastic components. To apply the interlocking structures on freeform surfaces of metal sheets, a flexible tool for a robot-based generation of such structures has to be investigated.

\subsection{Robot-based metal sheet processing}

In order to achieve efficient solutions for individualized structural products, robot-based (incremental) manufacturing of metal sheets is widely investigated. Thereby, single-point incremental forming (SPIF) and two-point incremental forming (TPIF) are the most frequently used methods for forming thin metal sheets. In both processes, a longitudinal path of linear motion along a specific outline is followed and after each turn, the vertical infeed and the outline geometry are adjusted. 


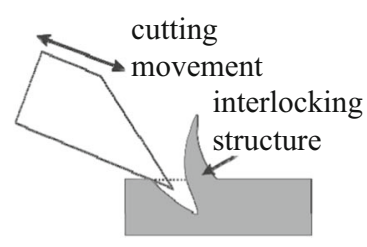

(a)

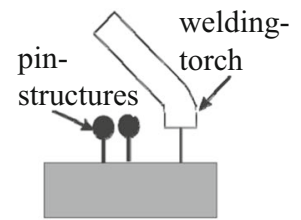

(b)

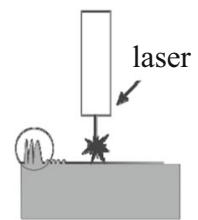

(c)

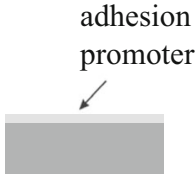

(d)

Fig. 2 Schematic illustration of bonding technologies for metal-plastic composites: (a) interlocking structures; (b) pin structures; (c) laser structures; (d) adhesive bonding

While the Amino company of Japan [6] has developed a special machine for incremental forming, most of the other published research from Bahloul [7], Jeswiet [8], Duflou [9], Micari [10], and Yang [11] using conventional CNC machine tools with specially designed non-cutting tools and appropriate workpiece mounting. In addition, research on robotassisted incremental forming is being conducted, for which one [12] or two [13] industrial robots are used. Thereby, industrial robots apply the essential forces for the forming operation. A different approach in SPIF is being pursued by Schäfer [14] with a robot-guided hammer tool driven by a servo motor and moved by a synchronous belt and eccentric. The required process forces are applied by the hammer tool, which acts as a robot end-effector linear to the external robot axis. He recommends using industrial robots with a large mass, high stiffness, and high degree of damping to keep vibration amplitudes low and process accuracy as high as possible. Furthermore, it is recommended to set the impact frequency of the hammer tool to be realized far above the first natural frequency of the industrial robot used, so that resonance and coupler vibrations are avoided.

While incremental forming of thin metal sheets is highly investigated, incremental freeform surface structuring creating interlocking structures is not examined. However, laser and welding-based structures, as presented in section 2.1, are already being applied using industrial robots. In order to achieve bonding strengths exceeding this, the robot-based application of interlocking structures is required.

\subsection{Chip and dust extraction}

For the iterative construction of components by combining additive with machining processes, it is of great importance to remove chips from the workpiece surface and surrounding dust from the air. For this purpose, it is necessary to collect chips and dust close to the cutting zone with a high chip collection rate in combination with an energy-saving extraction system. The systems used for this purpose must be able to remove the chips without restricting the machining process, especially when machining with industrial robots. The high operating costs of common extraction systems have motivated research work for a more efficient chip collection [15-18].

In general, a distinction is made between direct extraction at the tool and room extraction in the machine. The room extraction system is characterized by high air volumes at low pressure differences and is used to capture floating dust particles. When the chips are ejected from the tool, they have a high kinetic energy. Investigations to optimize chip collection in woodworking machines have shown that increasing the extraction speed is not suitable for generating an effective chip collection rate [19]. An effective chip collection is therefore only possible with direct extraction, which requires the smallest possible distance from the tool. The small distance to the chip formation is accompanied by restrictions regarding the geometric complexity of the components. One approach to effective low-energy chip collection is to use the kinetic energy of the chips. For this purpose, the extraction nozzle must be positioned in the direction of chip flow [20]. Gebhard [17] provided an approach for a solution. Here, the suction orifice is aligned during the milling process by the rotary axis according to the particle flow by using sensors and a CCD camera. However, this solution reaches its limits when machining bores or pockets and when using different tool lengths. Another approach consists of the extraction of chips through the tool. In the projects ASPIRATE [21] and SEPMAC [22], special tools with internal extraction were designed and manufactured. This made it possible to reliably extract small, lightweight chips of carbon fiber-reinforced plastics (CFRP) as well as glass fiber-reinforced plastics (GFRP). However, the extraction of metal chips is not possible with these tools. Up to the present day, there is a lack of new approaches that pursue adaptive, self-adapting suction or a reduction in the required suction energy.

\subsection{Summary}

As can be seen, the challenges described in Fig. 1 are currently being addressed with various solutions. However, most of the technologies presented here for increasing the bonding strength of metal-plastic composites cannot be transferred to the modular manufacturing process chain due to limited bonding strength, slow processes, or a lack of ability to transfer them to complex 3D geometries. Considering the existing technologies for robot-based metal sheet processing, there is a great potential in the adaptation of such technologies for surface structuring. Nevertheless, none of these technologies presently addresses mechanically applied free-form surface structuring. As mentioned before, adaptive or self-adapting 
suction hoods for chip and dust extraction of metal and plastic combinations still need to be addressed to integrate a subtractive manufacturing step in the modular process chain.

\section{Technical innovations in robot-based structuring and adaptive chip extraction}

Since there is still a lack of technologies in robot-based mechanically applied surface structures and adaptive chip extraction for metal-plastic composites, in the following sections, technical innovations and concepts will be described. Thereby, a surface structuring end-effector and an adaptive chip extraction hood for an in-process chip removal will be presented.

\subsection{Surface structuring end-effector}

As shown in section 2.1, there are different solutions for increasing the bonding strengths while manufacturing multimaterial composites based on metal and plastic. With the aim of integrating a highly efficient process with maximum flexibility and high bonding strength into the process chain described in chapter 1, an end-effector for the insertion of interlocking structures was developed. Thereby, the concept is based on SPIF and the results of the robot supported hammering tool. In order to find a concept for the end-effector, a performance evaluation of two passive force-based mechanisms (pneumatic system with spring and electromechanical system with eccentric discs and spring) has been carried out. The results have shown advantages for the electromechanical system with eccentric discs and a spring due to a simplified control and no need of valves or hose systems that have to be provided directly on the end-effector or its periphery.

In Fig. 3, a schematic illustration and a CAD model of the end-effector are shown. The kinematics of the structure generation consists of a punch and impact process. The required kinetic energy is introduced by an electric servomotor. This causes two eccentric discs to rotate in order to pre-tension the

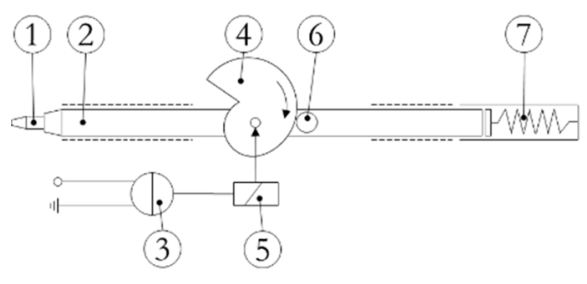

1 Structuring tool

6 Torque

2 Tool Carrier

3 Power Source

4 Eccentric Discs

5 Electric Engine

transducer

7 Compression Spring

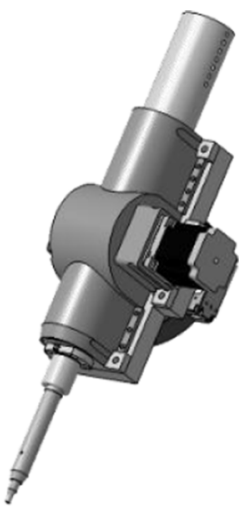

Fig. 3 End-effector for robot-based surface structuring tool carrier to enclose the compression spring module. After the peak of the eccentric disc is reached, the compression spring accelerates the tool carrier up to the point where the structuring tool hits the workpiece surface.

Since it is important to reduce vibrations and impact forces into the robot structure [14], there is no closed connection between the tool carrier and the robot. Here, the compression spring module takes over the task of both tool acceleration and shock absorption. The end-effector shown in Fig. 3 measures $570 \mathrm{~mm}$ in length, $180 \mathrm{~mm}$ in height, and $220 \mathrm{~mm}$ in width with a total weight of about $15 \mathrm{~kg}$. By having a small lightweight end-effector, mass inertia problems during the structuring process will be reduced (section 4.2). Based on preliminary investigations, a structuring frequency of $60 \mathrm{~Hz}$ is feasible for the end-effector. However, there is a risk of vibration excitation of the robot structure.

The structuring process is described as a linear punch and impact process at a specified angle. Hence, a continuous structuring process with constant speed along a given path is not possible. As a result of the continuous movement, lateral loads on the structuring tool would lead to deformation or even destruction of the interlocking structures.

\subsection{Chip removal}

Since the required surface qualities cannot be achieved by printing alone yet, the components must be reworked by machining. The resulting metal and plastic chips have to be removed for the following processes. In order to support the room extraction in the manufacturing cell, some concepts for direct extraction have been developed. After determining the necessary requirements (maximum size, weight, actuator system, etc.), several solutions were designed and evaluated. Due to the problems mentioned in section 2.3, which arise when a hose is carried alongside of the robot, an extraction hood was selected as the best solution (Fig. 4).

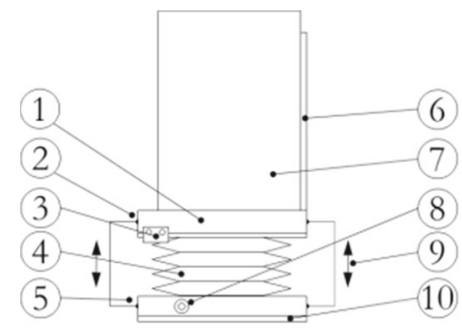

1 Adaptor ring 6 Adaptor board 2 Upper 7 Spindle house mounting 8 Extraction 3 Fastener socket 4 Gaiter 9 Hydraulic 5 Lower cylinder mounting 10 Brush

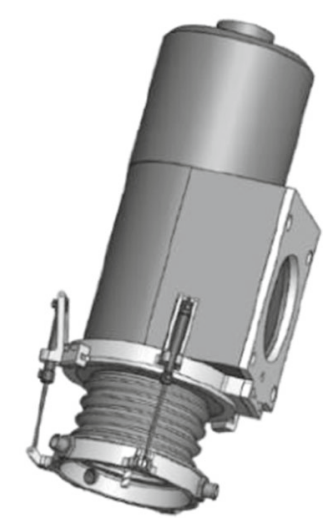

Fig. 4 Adaptive dust and chip extraction hood 
The extraction hood enables an in-process chip removal. It is mounted between the work spindle and the robot flange with an adapter plate and completely encloses the work spindle by an adapter ring. The suction hood is connected to the adapter by a closing mechanism and can be locked and unlocked by a socket pin, allowing the machining to be carried out without the extraction hood as well. The extraction hood itself consists of a flexible gaiter and a rigid ring element whereby the area around the tool is reduced and the chips are extracted close to the cutting zone.

The operating principle is based on the baffle plate principle. Thereby, the kinetic energy of the chips is reduced by the ring element. This enables an energy-efficient chip extraction close to the tool. Three socket adapters carry out the chip extraction. A suction hose is attached to each of the socket adapters, which are subsequently connected to a central tube. A brush ring is fixed in a groove at the bottom of the ring, which allows the extraction hood to fit flexibly on the component, as the brushes can deform and adapt to the structure of the component. Moreover, it allows air to enter the system during the extraction process and prevents the hood from being sucked onto the component surface. The suction hood can be moved by hydraulic cylinders, which are controlled by the robot software. Thus, the hood can be raised and lowered as well as tilted up to $30^{\circ}$ so that the hood can be adapted to the freeform surfaces to be machined. By lifting and lowering the suction hood, a tool change is ensured.

\section{Experimental investigations}

As a result of the challenges described in chapter 2, experiments were performed to implement the process chain. Thereby, challenges in increasing the interlayer bonding strength of the extruder-based applied plastic and motion studies for a future application of the robot-based surface structuring end-effector were considered. To improve the interlayer strength, various bonding techniques were investigated. Both the creation of interlocking structures between the plastic layers and the enlargement of the bonding surface to increase the adhesive strength are considered. As described in section

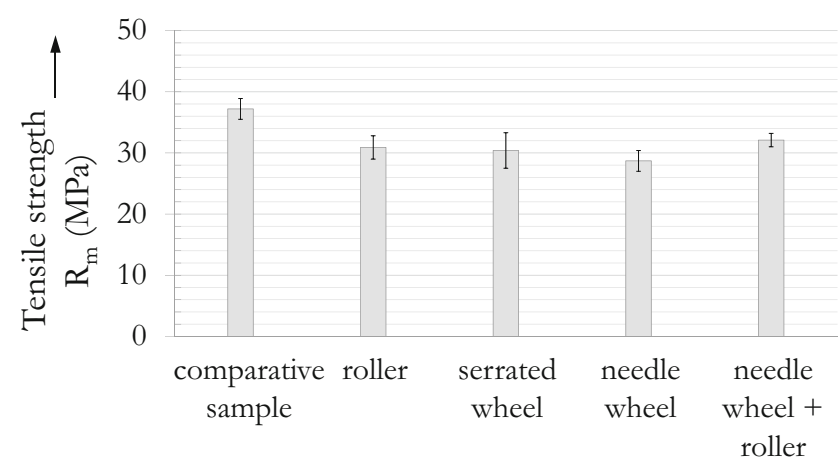

Fig. 6 Results for the interlayer strengths

3.1, the structuring process cannot be performed continuously due to a deformation or destruction of the interlocking structure produced. By quickly accelerating and decelerating between two or more points, vibrations are introduced in the robot structure, possibly resulting in a failure of the robot or in high process deviations. Hence, different experiments on the process design of the surface structuring were carried out.

\subsection{Interlayer bonding strength in additive material application}

Three different approaches to improve the interlayer strength were investigated (Fig. 5). On the one hand, the surface area between the layers was increased; on the other hand, interlocking structures were created to connect two layers mechanically. For increasing the surface area of the plastic layer, a serrated wheel is used. By processing the last applied layer by the wheel, little sinks are created that can be filled by the next layer. For interlocking several layers, a needle wheel is used. By puncturing several layers with the needle wheel, materials from higher layers are pushed into lower ones creating a mechanical connection.

The two approaches did not result in a higher interlayer strength. By modifying the layers with the needle wheel and the serrated wheel, additional notches are introduced lowering the bonding area and therefore the bonding strength of the material used from $37.2 \pm 1.2$ to $30.4 \pm 2.9 \mathrm{MPa}$ for the serrated and to $28.7 \pm 1.7 \mathrm{MPa}$ for the needle wheel. By compressing the modified layers with a roller, a slight

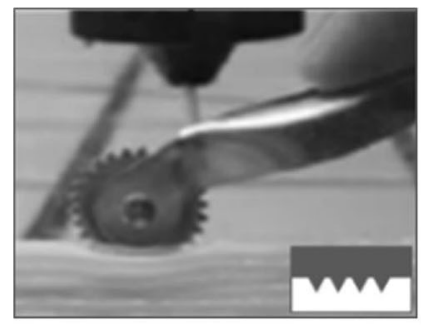

(a)

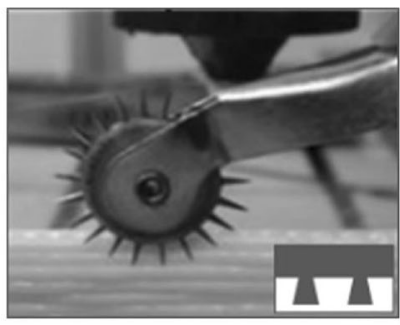

(b)

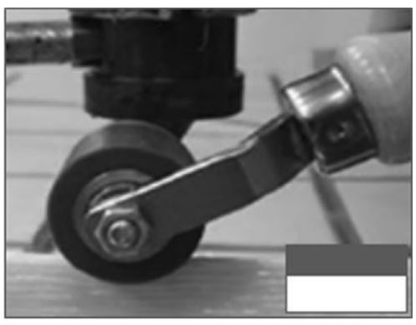

(c)

Fig. 5 Tools used for improving interlayer strength. (a) Serrated wheel for enlarged surface. (b) Needle wheel for interlocking structure. (c) Roller for compressed layers 


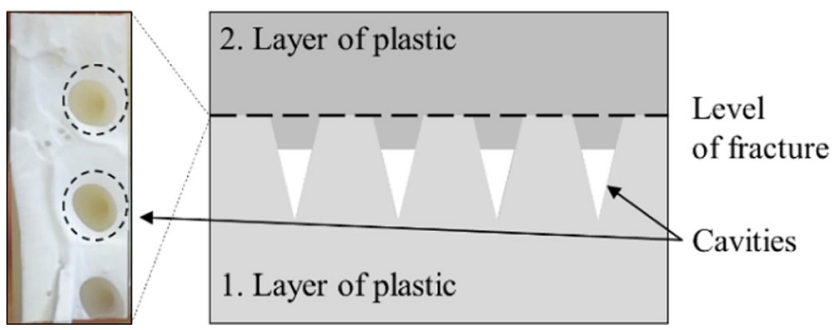

Fig. 7 Cavities caused by the needle wheel and serrated wheel between the plastic layers

improvement compared to the needle wheel can be achieved. The resulting different interlayer strengths are shown in Fig. 6.

Further investigation showed notches and air pockets on the breaking edge, which led to the observed reduction in the tensile strength. On the one hand, the notches and pockets can be caused by water residues in the used material, although it was dried for several hours. On the other hand, the use of the serrated wheel or the needle wheel resulted in structures that could not be filled by material of the next layers, which led to the observed defects (Fig. 7).

Therefore, mechanically induced modification by puncturing or deforming layers already printed is no longer performed due to no significant improvement of the bonding strength. The process parameters (e.g.. the printing temperature, layer temperature, cooling rate of the printed material) as shown in the previous paper [1] seem to have a higher potential to improve the cohesion between the layers. To reach the maximum load of $44 \mathrm{MPa}$, further approaches regarding the process parameters and the printing process itself need to be investigated.

\subsection{Process design of surface structuring}

In order to realize a robot-guided surface structuring process, different point to point movements with a KUKA KR $60 \mathrm{HA}$ and a mass dummy end-effector of about $20 \mathrm{~kg}$ have been carried out. For measuring the positioning accuracy, a laser tracking system was used.

In Table 1, the experimental data for the point to point movements are given.

Table 1 Experimental data for point to point movements

\begin{tabular}{llll}
\hline No. & Distance in $\mathrm{mm}$ & $\mathrm{t}_{\text {stop }}$ in $\mathrm{s}$ & $\mathrm{v}$ in $\mathrm{m} / \mathrm{s}$ \\
\hline 1 & $6 ; 18 ; 30$ & 1 & 0.1 \\
2 & $6 ; 18 ; 30$ & 1 & 2.0 \\
3 & $6 ; 18 ; 30$ & 2 & 0.1 \\
4 & $6 ; 18 ; 30$ & 0 & 0.1 \\
\hline
\end{tabular}

The used robot has a position repeatability of $\pm 0.05 \mathrm{~mm}$ by working with nominal load capacity of $60 \mathrm{~kg}$

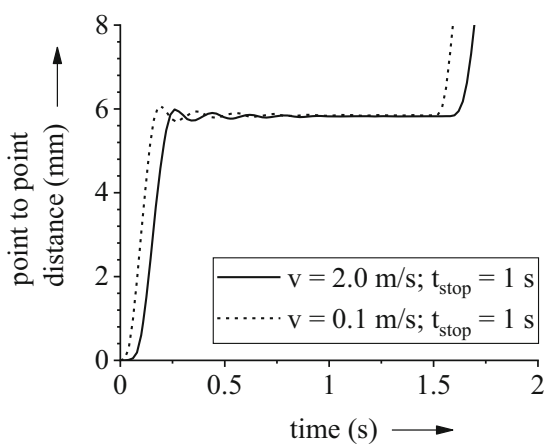

Fig. 8 Vibration behavior of robot-guided end-effector for point to point distance of $6 \mathrm{~mm}$

However, Fig. 8 shows a position accuracy of $\pm 0.1 \mathrm{~mm}$ due to the effects of mass inertia.

It was also found that even after reaching a critical velocity, the amplitudes of the induced vibration remain almost unchanged, as can be seen in Fig. 9.

Considering that the time of the structuring process is about $1 \mathrm{~s}$, the damping time of $1.5 \mathrm{~s}$ has to be added to the robot path planning. In order to achieve a significant reduction of mass inertia vibrations, a velocity less than $0.01 \mathrm{~m} / \mathrm{s}$ and a stop time of $2 \mathrm{~s}$ have to be used.

In Fig. 10, the results for that vibration behavior are given. Due to the end-effector presented in section 3.1 (mass of 15 $\mathrm{kg}$ ), less mass inertia vibration will occur. However, further investigations in path planning and vibration transmission have to be done.

\section{Conclusion and outlook}

This paper presents the current challenges for a combined robot-based manufacturing process and the machining of multi-material parts based on metal and plastic. At first, the related works for robot-guided surface structuring, chip extraction, and milling of multi-material parts are discussed. Components of a manufacturing cell for the production of metal-plastic parts, like an end-effector for a robot-based freeform surface structuring process and an in-process chip

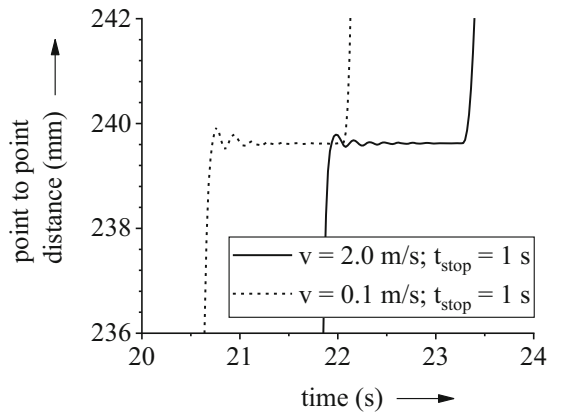

Fig. 9 Vibration behavior of robot-guided end-effector for point to point distance of $30 \mathrm{~mm}$ 


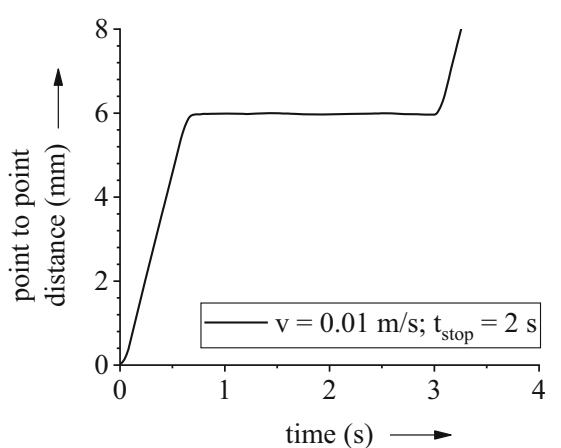

Fig. 10 Vibration behavior of robot-guided end-effector for point to point distance of $6 \mathrm{~mm}$

extraction system, are presented. In order to investigate two of the main challenges, experiments were carried out on the interlayer strength of the plastic part. The use of interlocking effects has shown no increase in interlayer strength.

Furthermore, first motion studies for the surface structuring process were investigated using a mass dummy. Here, a need of stopping time was shown due to the effect of vibrations caused by mass inertia.

To show the whole manufacturing process on a demonstration part, further experiments have to be performed with the end-effector and extraction hood. For the structuring process, reaction forces have to be analyzed, a proper path planning algorithm for free-form surfaces has to be determined, and experiments with different compression spring loads for specific surface materials have to be carried out. The in-process chip extraction system needs to be tested regarding collision avoidance strategies and usability. In subsequent steps, the technical performance of the system will be experimentally tested with regard to the achievable chip collection rate and energy efficiency.

Availability of data and material The results presented in this paper are based on data generated in-house. If you are interested in CAD data, measurement results, or other information, please contact us by e-mail.

Code availability Not applicable.

Funding Open Access funding enabled and organized by Projekt DEAL. This paper is part of the research project "HyLight3D," which is funded by the Federal Ministry of Education and Research, in the context of "KMU-Innovationsoffensive Produktions-forschung." The entire project consortium is composed of one institute from TU Braunschweig (Institute of Machine Tools and Production Technology) as well as three SME industrial partners (Robot-machining $\mathrm{GmbH}, 3 \mathrm{D}$-Schilling $\mathrm{GmbH}$ and Robotized $\mathrm{GmbH})$.

\section{Declarations}

Conflict of interest The authors declare no competing interests.

Open Access This article is licensed under a Creative Commons Attribution 4.0 International License, which permits use, sharing, adaptation, distribution and reproduction in any medium or format, as long as you give appropriate credit to the original author(s) and the source, provide a link to the Creative Commons licence, and indicate if changes were made. The images or other third party material in this article are included in the article's Creative Commons licence, unless indicated otherwise in a credit line to the material. If material is not included in the article's Creative Commons licence and your intended use is not permitted by statutory regulation or exceeds the permitted use, you will need to obtain permission directly from the copyright holder. To view a copy of this licence, visit http://creativecommons.org/licenses/by/4.0/.

\section{References}

1. Dröder K, Reichler A, Mahlfeld G, Droß M, Gerbers R (2019) Scalable process chain for flexible production of metal-plastic lightweight structures. In: Procedia CIRP 85:195-200

2. Brand M, Kühn M, Müller A, Klaus K (2016) Enhancing the tensile strength in hybrid Metal-FRP-Materials through various interlocking structure patterns. EURO HYBRID - Materials and Structures, Kaiserslautern, Germany, 251

3. German Patent Description DE 60019560 T2: Brake plate and method and apparatus for manufacturing same, 02-23, Arbesman R, Toronto - Ontario, CA(2006).

4. Skhabovskyi I, Batista NL, Damato CA, Reis RP, Botelho EC, Scotti A (2017) Appraisal of fiber-metal laminate panels reinforced with metal pins deposited by CMT welding. Elsevier, Composite Structures 180:263-275

5. Roesner A et al (2011) Laser assisted joining of plastic metal hybrids. Elsevier. Physics Procedia 12-2:370-377

6. Amino $\mathrm{H}$ et al (2002) Dieless NC forming of automotive service parts. Technology of plasticity, Yokohama, Japan:1015-1020

7. Bahloul R, Arfa H, BelHadjSalah H A study on optimal design of process parameters in single point incremental forming of sheet metal by combining Box-Behnken design of experiments, response surface methods and genetic algorithms. International Journal of Advanced Manufacturing.

8. Jeswiet J (2001) Incremental single point forming. Transactions of the North American Manufacturing Research Institution of SME, XXIX: 75-79

9. Duflou J, Szekeres A (2005) Force measurements for single point incremental forming: an experimental study. Shemet, Erlangen

10. Filice L, Fratini L, Micari F (2002) Analysis of material formability in incremental forming. Cirp Annals-Manufacturing Technology 51-1:199-202

11. Kim T (2000) J, Yang D Y. Improvement of formability for the incremental sheet metal forming process. International Journal of Mechanical Sciences 42-7:1271-1286

12. Lamminen L (2005) Incremental sheet forming with an industrial robot - forming limits and their effect on component design. Advanced Materials Research, Proceedings of the 11th Int. Conference on Sheet Metal SHEMET, Nürnberg, 457 - 464

13. Department of Production Systems at the Ruhr-University Bochum LPS, Online: www.lps.ruhr-uni-bochum.de/arbeitsgruppen/ automatisierung/roboforming, Retrieved 25.03.20.

14. Schäfer T (2007) Verfahren zur hämmernden Blechumformung mit Industrieroboter. Universität Stuttgart, Jost-Jetter Verlag, Heimsheim, Dissertation

15. Blecken J (2004) Optimierung der Staub- und Späneerfassung in stationären Holzbearbeitungsmaschinen. Dissertation der Technischen Universität Braunschweig 
16. Dressler M (2007) Simulation von Späneerfassungsvorgängen in Absaughauben bei holzbearbeitenden Maschinen. Dissertation der Universität Stuttgart

17. Gebhard A, Absaugtechnik beim Zerspanen von Leichtbauwerkstoffen. Online: www.ipa.fraunhofer.de/content/ dam/ipa/de/ documents/Kompetenzen/Leichtbautechnologien/ Produktblatt_Absaugung de.pdf, Retrieved 25.03.2020.

18. Schneider M, Stehle T, Möhring H, Absaugung von Span- und Staubpartikeln. wt Werkstattstechnik online, Jahrgang 108 (2018).

19. Heisel U, Tröger J, Haag M, Dressler M, Neue Wege zur Verbesserung der Späneerfassung in Holzbearbeitungsmaschinen (Teil 1, 2 und 3). HK - Holz- und Kunststoffbearbeitung, (1999).

20. Fraunhofer Gesellschaft - Institut für Produktionstechnik und Automatisierung IPA, Innovationen für die Leichtbaubearbeitung.
Online: www.ipa.fraunhofer.de/de/presse/presseinformationen/ 2015-09-15_innovationen-fuer-die-leichtbaubearbeitung.html

21. ASPIRATE, Increase of productivity, safety, greenness and cleanliness in the machining of carbon fibre-reinforced composites. European Commission, CORDIS, Final Report Summary, Online: cordis.europa.eu/project/id/232127/reporting, Retrieved 25.03.20

22. SEPMAC: Sustainable and economic production of magnesium components. European Commission, CORDIS, Objective, Online: cordis.europa.eu/project/id/G1RD-CT-1999-00157, Retrieved 25.03.20.

Publisher's note Springer Nature remains neutral with regard to jurisdictional claims in published maps and institutional affiliations. 